\title{
De Inglaterra para Portugal: Lições a Aprender sobre Cuidados Paliativos
}

\author{
From England to Portugal: Lessons to be Learned about Palliative Care
}

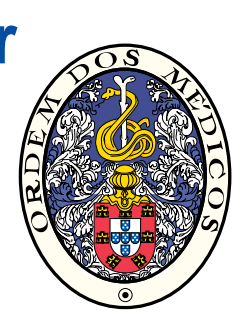

Ana CARDOSO 1

Acta Med Port 2014 Jan-Feb;27(1):6-8

Palavras-chave: Cuidados Paliativos; Continuidade de Cuidados ao Doente; Portugal; Inglaterra; Cuidados Terminais.

Keywords: Palliative Care; Continuity of Patient Care; Portugal; England; Terminal Care.

Mr. Jones (nome fictício), 59 anos, com o diagnóstico de adenocarcinoma do pulmão e metástases hepáticas, encontra-se no domicílio com dor, náuseas e vómitos.

A enfermeira da comunidade que o visita, depois de discutir as diferentes hipóteses com o doente e a sua família, decide referenciar para a Unidade de Cuidados Paliativos (o Hospice) para controlo de sintomas em internamento.

Na reunião diária do Hospice, onde os presentes são os habituais elementos de uma Equipa Multidisciplinar - médicos, enfermeiros, fisioterapeutas, assistentes operacionais, assistente social, secretárias clínicas e também os estudantes de Medicina e Enfermagem - a decisão é unânime: Mr. Jones deve ser admitido o mais rapidamente possível, o que acontece no dia seguinte.

Duas semanas mais tarde, melhora consideravelmente e volta para sua casa, acompanhado por um pacote de apoios sociais.

\section{Atitude face aos Cuidados Paliativos}

Inglaterra, berço dos Cuidados Paliativos Modernos, muito tem investido, aprendido com os seus erros e evoluído nesta área sendo, portanto, um bom exemplo para Portugal. ${ }^{1}$

A minha impressão é de que no Reino Unido há uma atitude diferente face aos cuidados terminais e à morte. Tal como fazer a visita médica da manhã na enfermaria, é natural observar o doente em fim de vida.

Assim como é natural prescrever morfina, midazolam e perfusões subcutâneas contínuas - faz parte do dia-a-dia, quer seja no Hospice, no Hospital ou na Comunidade. Ou algum médico recusar-se-ia prescrever paracetamol para um sintoma como a febre?
E é natural sentir aquele alívio de missão cumprida quando o doente falece tranquilamente no seu local de preferência na companhia da sua família e amigos - tal como o sente o cirurgião que consegue aquela incisão que salva a vida do doente.

\section{Acessibilidade}

Em Portugal, o processo de acesso a Cuidados Paliativos gratuitos é rígido e burocrático.

Revisitemos um processo de referenciação para a Rede Nacional de Cuidados Continuados Integrados ('a Rede'). Por exemplo, um doente que está no seu domicílio e que é visitado pelo seu Enfermeiro de Família. A esposa pede 'para que ele não morra em casa, pois não seria capaz de dormir na mesma cama onde o marido faleceu'. O Enfermeiro decide então referenciar para uma Unidade de Cuidados Paliativos da Rede. Para isso, além da sua própria avaliação, necessita ainda da opinião de dois outros profissionais: Médico de Família e Assistente Social. A informação dos três elementos é transmitida a um colega - o elemento sinalizador - que dá entrada da informação na plataforma virtual da Rede. Depois de completo este processo (que por si só é moroso, mas que pode tornar-se ainda mais se algum destes elementos se encontrar ausente), a informação é enviada à Equipa Coordenadora Local $(E C L)$ da RNCCl que, depois de a avaliar e se concordar com a referenciação, reencaminha para a Equipa Coordenadora Regional (ECR). ${ }^{2}$

Entretanto, na plataforma o Enfermeiro vai lendo: 'para avaliar'; depois, 'em avaliação'; uns dias mais tarde, 'aguarda documentação' e finalmente, duas semanas depois, o tão desejado 'aguarda vaga'. Enquanto isto, vai

\section{Willow Wood Hospice}

Situa-se em Ashton-under-Lyne, cidade do Norte de Inglaterra, a $10 \mathrm{~km}$ para Este de Manchester. A sua área de referenciação corresponde a nove cidades, com um total de 253000 habitantes, aproximadamente. Uma das características desta população é a sua diversidade de nacionalidades (sendo as maiores comunidades provenientes da Polónia, Paquistão, Bangladesh, Itália, Índia, China e Portugal) e respectivas religiões. ${ }^{4}$

Os locais costumam dizer: 'viver aqui é como um buraco - uma vez dentro dele, não se consegue sair!', tal é a forma harmoniosa e interessante com que britânicos e estrangeiros se misturam.

1. Willow Wood Hospice. Ashton-under-Lyne. Reino Unido.

Recebido: 23 de Dezembro de 2013 - Aceite: 21 de Janeiro de 2014 | Copyright $\odot$ Ordem dos Médicos 2014 
visitando o doente. Infelizmente, a sua condição agrava e encontra-se agora nas últimas 24 horas de vida. Na incerteza de quanto tempo a vaga para a Unidade de Cuidados Paliativos poderá ainda demorar e sob pressão da família, o Enfermeiro não tem outra solução. Telefona para o 112 e envia o doente para a urgência do Hospital, onde falece umas horas mais tarde.

A dificuldade deste processo não está relacionada com os profissionais envolvidos, que fazem um trabalho excelente dentro das suas possibilidades, nem com as ECL e ECR, que têm a difícil missão de gerir os seus recursos.

No entanto, em Inglaterra é bem mais simples. Qualquer profissional de saúde que observa o doente pode facilmente referenciar, enviando por fax um formulário ou contactando os seus colegas telefonicamente.

Sem sinalizador, sem passwords, sem plataformas de referenciação, sem documentos de identificação, sem assinaturas de consentimentos informados, sem equipas locais, sem equipas regionais, sem listas de espera.

Portugal grita por esta simplicidade, pela desburocratização. E tem também de aprender a confiar. No exemplo apresentado, o Enfermeiro rapidamente percebeu que aquele doente necessitava de internamento em Cuidados Paliativos. Alguém poria em causa esta decisão? Porque não tem ele independência para referenciar? Porque necessita de outras avaliações? E porque necessita de uma Equipa Local ou de uma Equipa de Gestão de Altas (EGA) que não conhecem o doente e que por vezes são responsáveis pelo 'chumbo' de doentes nas referenciações para Unidades de Paliativos. Isto gera nos colegas referenciadores desilusão e perda de confiança porque 'afinal o trabalho que tiveram não serviu de nada'. Dos colegas do Hospital cheguei a ouvir: 'Para quê referenciar? Depois a EGA envia os doentes para casa... então prefiro mantê-los internados, porque assim posso prescrever a medicação de que necessitam'.

Ainda em Portugal, lembro-me do entusiasmo da população e dos profissionais que a Unidade de Cuidados Paliativos gerou aquando da sua inauguração que, pouco tempo depois, se transformou em desilusão. Afinal a Unidade estava lotada com doentes que viviam a mais de $100 \mathrm{~km}$ de distância e os seus conterrâneos tinham de ir para Unidades também muito distantes. A população não percebia 'porque é que os de lá vinham para cá, e os de cá iam para lá'.

No Reino Unido existem Hospices localizados em todas as comunidades. Este facto cria na população local um sentimento de protecção, isto é, esperam nunca precisar dos seus serviços, mas reconhecem o seu valor e protegem-no com um carinho especial. Os Médicos de Família são unânimes: 'É muito difícil trabalhar em sítios em que não existe um Hospice, por isso temos muita sorte'.

\section{Continuidade de cuidados}

Por seu lado, na Unidade de Cuidados Paliativos pertencente à Rede, os doentes mostravam a sua angústia: 'Eu sei que agora estou melhor, mas se o meu cancro pro- gredir, eu posso voltar para cá?' e, embora frequentemente a resposta fosse um sorriso (amarelado) e um 'Sim, o Centro de Saúde voltará a referenciar', a verdade é que em muitos casos não os voltava a ver.

Além disso, apesar de terem os sintomas sob controlo, continuavam a ser doentes frágeis, idosos na sua maioria, com elevada dependência, e com condições sociais difíceis (isolamento social, casas desadequadas às suas necessidades, ...) que, aliado à dificuldade em conseguir respostas na comunidade (lares, por exemplo), resultava na impossibilidade de dar altas e consequentes internamentos com duração superior a 100 dias.

No Reino Unido, os doentes têm a tranquilidade de saber que, na alta, vão para casa com um conjunto de benefícios sociais (pensões para o próprio e para o seu cuidador, apoio domiciliário, equipamento como camas articuladas ou barras de apoio colocadas em casa pelos serviços sociais) e onde são visitados pelas equipas da comunidade.

Sabem também que podem voltar ao Hospice uma vez por semana para frequentarem a Unidade de Dia, onde podem usufruir de fisioterapia, hidroterapia, terapias complementares, apoio espiritual, podologia, cabeleireiro e maquilhagem; podem contactar a Equipa telefonicamente 24 horas por dia e, se a situação agravar, podem ser readmitidos no internamento.

A alta dos doentes mais dependentes é, em geral, efectuada para o lar de idosos, considerado o domicílio do utente e, portanto, este continua com os mesmos direitos que qualquer outro cidadão.

Em Portugal, continuamos a ver os lares de idosos como locais independentes e não como parceiros nos cuidados. Mas esta colaboração é essencial. Eu posso dar o exemplo de Montemor-o-Novo, onde me formei como Médica de Família. Em algumas ocasiões, recorri à Casa de Repouso local para as últimas 48 horas dos doentes e a proprietária não cobrou absolutamente nada, porque eticamente sentiu que estava a prestar um serviço à sua comunidade.

Para melhorar a continuidade e partilha de informação entre os múltiplos profissionais de saúde, utilizamos o "Multiprofessional Toolkit", um boletim de saúde individual permitindo aos doentes o registo de informação clínica e a sua declaração antecipada de vontade, que poderia ser implementado em Portugal. ${ }^{3}$

\section{Formação}

Por fim, o problema da formação específica. No Reino Unido, nem todos os profissionais que iniciam uma carreira em Cuidados Paliativos têm formação específica. O que existe é um grande sentido prático em acarinhar os que mostram pelo menos uma pequena curiosidade e a Equipa responsabiliza-se por transformar este interesse em paixão pela área. A necessidade de formação específica surge depois, de forma natural, na pessoa conquistada. De facto, qual de nós investe dinheiro e tempo em algo que nunca experimentou antes?

O Willow Wood Hospice tem contribuído para este processo ao permitir que diferentes profissionais frequentem 
estágios formativos. De Portugal, recebeu duas internas de Medicina Geral e Familiar (MGF), uma enfermeira e uma reflexologista; e do Brasil recebeu uma psicóloga. Em 2014, aguardamos a visita de outros profissionais portugueses.

Uma semana depois recebemos um telefonema da Sala de Observação da Urgência hospitalar. Mr. Jones foi admitido com uma hemorragia grave e necessita agora de cuidados terminais. O seu local de preferência é o Hospice. Ao abrigo do protocolo entre as duas instituições, é imediatamente transferido. À sua chegada, ele diz 'Estou tão aliviado por estar aqui!'. Mr. Jones faleceu no Hospice umas horas mais tarde, tranquilamente, com a sua família e amigos presentes.

\section{REFERÊNCIAS}

1. About Palliative Care. London: Cicely Saunders International; [Consultado 2013 Dez 9]. Disponível em: http://www.cicelysaundersfoundation. org/about-palliative-care.

2. Unidade de Missão para os Cuidados Continuados Integrados. Modelo de Referenciação de Utentes. Lisboa: Rede Nacional de Cuidados Continuados Integrados; 2009.

3. Tapley M, Cerdeira M, Cardoso A, Vallantine K. The multiprofessional

\section{AGRADECIMENTOS}

A autora gostaria de agradecer a Tiago Villanueva, BMJ Editorial Registrar, pelo apoio prestado e pelos importantes comentários e sugestões.

\section{CONFLITO DE INTERESSES}

A autora declara que não houve conflito de interesses na realização deste trabalho.

\section{FONTES DE FINANCIAMENTO}

A autora declara a inexistência de fontes de financiamento externas.

toolkit - improving communication about patient choices for care. $\mathrm{Br}$ Med J Support Palliat Care. 2011;1:269-70.

4. Adapted from data from the Office for National Statistics licensed under the Open Government Licence v.1.0. Newport: Office for National Statistics; [Consultado 2013 Dez 4]. Disponível em: http://www.ons.gov.uk/ ons/guide-method/census/2011/index.html. 


\section{De Inglaterra para Portugal: Lições a Aprender sobre Cuidados Paliativos \\ Acta Med Port 2014:27:6-8}

Publicado pela Acta Médica Portuguesa, a Revista Científica da Ordem dos Médicos

Av. Almirante Gago Coutinho, 151

1749-084 Lisboa, Portugal.

Tel: +351218428 215

E-mail: submissao@actamedicaportuguesa.com

www.actamedicaportuguesa.com

ISSN:0870-399X | e-ISSN: 1646-0758

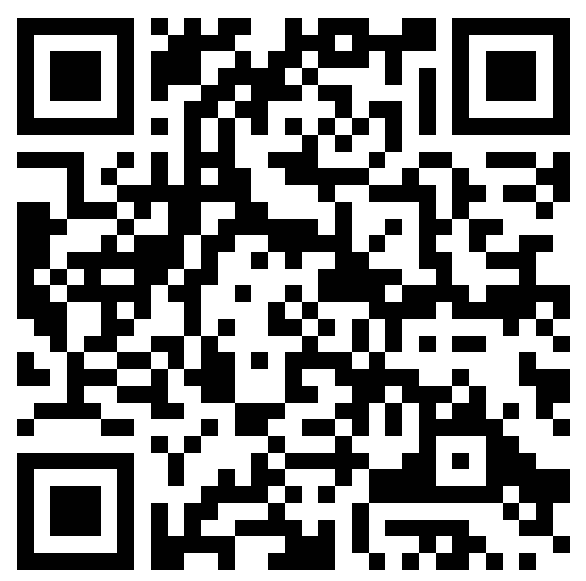

